\title{
Motivate Online Users by Moderating and Providing Tasty Testing Experiences
}

\author{
Weiping Huang ${ }^{1}$, Minna Pakanen ${ }^{1 \& 2}$, Lotta Haukipuro ${ }^{1}$, Satu Väinämö ${ }^{1}$, Leena Arhippainen ${ }^{1}$ \\ ${ }^{1)}$ Center for Ubiquitous Computing \\ P.O Box 4500 \\ ${ }^{2)}$ INTERACT Research Unit \\ P.O Box 8000 \\ 90014 University of Oulu, Finland \\ 90014 University of Oulu, Finland
}

firstname.lastname@oulu.fi

\begin{abstract}
Online user communities and social networks are both used for user involvement in innovation process. Even though both of them have active participants as key driving force for innovation, they are still not the same. Therefore, this study investigated citizens' motivations to participate in an online user community, and compared how these motivations differ from motivations to participate in social networks. We conducted a UX study with 51 participants in total. The findings revealed that the role of moderator is a crucial for active participation and keeping up users' motivation. In addition, our findings suggest that an online living lab community shares common characters with other social networks, but it cannot be replaced by social media. The differences between online living lab and social network community are related to user motivations, and the needs of the customers and researchers for living lab activities. In this paper, we present a process of Oulu Urban Living Lab with user involvement supported by the PATIO online user community. Also requirements, system architecture and a new version of PATIO are described. Even though an amount of participants in our living lab study is relatively small, we want to share these insights for professionals of industry and academy.
\end{abstract}

\section{INTRODUCTION}

Living labs are getting more and more popular in involving users into innovation process of products and services. The living lab has been referred as a user-centered innovation environment based on daily practice and research, involving users to open innovation process in a real-life context, considering of sustainable value creation [6]. One of the latest definitions describes living lab as user innovation creation in community with business stakeholders involved, either online or offline [5]. With these concepts, online living lab community raises its importance in terms of connecting relevant stakeholders and providing services accordingly, to support the innovation creation activities in living labs.

Prior research has investigated user motivations to participate in testing activities [33][21]. In order to motivate participants, living labs should be able to provide interesting test projects, incentives, and feedback for the test users [21]. Rewards are important as test participants may be the sources of ideas and innovations, and thus their efforts should be compensated fairly [11]. Rewards, however are not the most important motivating factors for the living lab participants. Intrinsic motivations, such as learning new things, stimulating curiosity, and being entertained are even more important for the participants [33]. These intrinsic motivations are found to be important also when establishing long-term engagement in living lab [22]. A sense of efficacy, a sense of community, and fun are the most important factors affecting users' participation willingness in an online innovation community [3]. Also different communities fulfill different goals for diverse types of users, and users have different expectations, engagement, and intentions when participating in different communities [33].

When people have been registered in an online user community as a voluntary basis, they are motivated and interested in the product or service development, and thus provide added value for companies and organizations [21]. However, not all the living lab members are active especially in large living labs. According to Lievens et al. [22] from large user database with over 19000 users, only $1.1 \%$ are active (have participated at least six times within four years), $22.4 \%$ are sleeping (have participated in a few tests, not active at the moment), and majority, 76,5\%, are passive meaning that they have participated only once in testing activity. It is important to establish a relationship with test participants via frequent contact to them, in order to make them feel engaged and show that their inputs are considered [22].

Living labs are involving users as equal co-creators with the other stakeholders in real-world settings [2]. This makes living labs different from other innovation approaches. According to Schuurman and De Marez [32], living labs have a high degree of realism and a high degree of (user) involvement. Users are involved in all stages of the product development lifecycle which makes it unique against typical field trials or user testing [4].

As users are seen as the innovators in the living lab approach, methods used for user-centered development need to be adjusted accordingly. Key principles of living labs are indicated as openness, user involvement, sustainability as well as the value generation from economy, business and users [34]. The activities taking place at living labs comprise of user and producer co-creation, new opportunities exploration, experiment in user community and the products and services evaluation [9]. A good example of benefits of using an online user community for cross-border studies in order to gather 
certain user groups' needs and evaluate companies' solutions is the experiment, which was carried out in Finland and Karelia Republic of Russian Federation [17]. An idea of utilizing PATIO user involvement tool in such research context was presented to the informants, and they perceived it as suitable for engaging people with disabilities for development as well as for social activities.

Living lab has been attempted to connect with social network sites, for example, living lab approach for the usercentered innovation with three dimensions of technology, business, and users is discussed in [11]. UXModeler use social network to bring software engineering and innovation together [20]. Another interpretation of living lab shows three similar factors of technology, enterprises, and society [1], where social media is used as a method of society to connect users in the living lab. Social web has been analyzed as an innovation accelerator, where social web is seen as innovation ecosystem containing a software platform, business ecosystem, and user experience [25]. More business opportunities could be received by supporting application development based on the platform, with thoughtful design of the software solution. Secondly, the social web business ecosystem refers to different stakeholders who are communicating and influencing each other, but have diverse motivations, targets, and working processes. Social web takes important role in the user-centered innovations by support of user communities. Social media allows an unprecedented opportunity for individuals and entrepreneurs to engage in social interaction in a scale and in a manner that was not possible before social media became widely popularized [15]. As social media services are built on user participation, content creation, and communication, they provide a promising means for involving users in design and innovation activities [24]. Therefore, social media also might facilitate interactions in living lab environment. However, there is also a risk of losing users by using social media due to the information overload. [25]

Prior research has investigated user motivations to participate in testing activities [21][33], but user motivations to participate for longer period of time within living lab leaves room for further investigation [22]. Also understanding the differences between social media and online user community requires more research, especially from a user point of view.

In this paper, we first introduce the process of OULLabs (Oulu Urban Living Lab). Then, we present the PATIO user community and user involvement tool and its requirements and the system architecture. Next, we describe the user experience study and its findings of users' motivations to participate in an online user community, and discuss of similarities and differences between social networking sites and online user community. Then, we present the new system design and implementation with an emphasis on user involvement approach. Finally, we discuss and conclude the paper.

\section{PROCESS OF OULLABS}

OULLabs is founded 2010 and managed by the University of Oulu. OULLabs is network-like living lab and aims to provide a diverse environment for innovation, research,

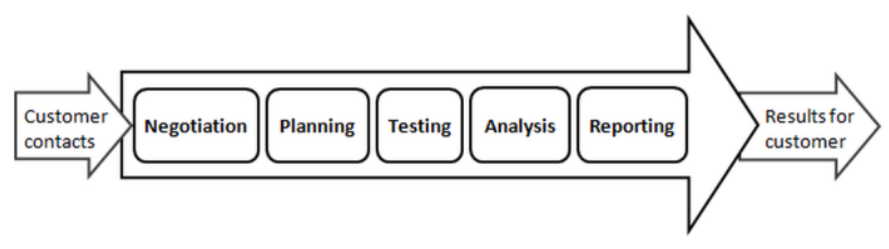

Fig. 1. The process of Oulu Urban Living Lab

development and testing of new product and services in authentic environment with real users. OULLabs operates as a one-stop-shop entity from where a customer can easily order a comprehensive living lab project for a new product or service [18]. The test project spectrum varies from idea generation to evaluation and testing, for instance, mobile applications, device designs and public online services.

The process of OULLabs (Fig. 1) has five phases: negotiation, planning, testing, analysis and reporting. The process begins with the customer contact. The customers can be e.g. company, organization, city, or research entity. Firstly, in the negotiation phase, the project goals and objectives are discussed with the customer. Based on the negotiations, specialists from OULLabs create the initial plan, which will be the basis of the contract and agreement and the research plan. In this phase, schedule, objectives and expected results as well as methods, tools and target user groups are defined in more detail. In the planning phase, the preparation of the tests and user recruitment are done. In the testing phase, the citizens test, evaluate and give feedback of ideas, concepts, prototypes or new products and services. The data is collected through various methods and tools both online and on-site. Then data is analysed by specialists from OULLabs if agreed so with the customer. The process finishes with presenting and/or delivering the results to customer to be used for further development of products or services. Based on the results and customer needs, the additional tests or other services of OULLabs can be offered.

\section{PATIO ONLINE USER COMMUNITY}

In this chapter, we introduce the requirements and system architecture of PATIO online user community and user involvement tool.

\section{A. System Requirements}

The PATIO service is aiming to support the process of living lab activities with the participation of citizens into the innovation co-creation. The requirements of establishing such online user community has been identified here from the aspects of roles, tasks and systems.

The PATIO users (e.g. test participants, online respondents) and system administrator are playing the crucial roles in the online user community. To participate in the living lab testing activities, user registers to the system and is then able to login and manage own personal profile on the online user community. System administrator takes the responsibility of user management, activity management and rewards management. Also, important roles in involving in the living lab process and PATIO are the test project manager and 
developers (e.g. customers' service or product developers). For them a smooth communication with test participants and reporting of valuable test result are the most relevant requirements.

One of the primary objectives of living labs is a possibility to conduct the innovation co-creation activities in the real-life contexts with citizen participation. Accordingly, the main functions of PATIO system are designed to support these actions, which include setting up the online testing environment, motivating and recruiting citizens to participate in the activities, maintaining the communication channel, as well as implementing various test and research methods for the data collection and analysis.

When comparing with the autonomous of social media, the activities taking place in PATIO are monitored. Activity management should be enabled by system administrator and/or activity owner, with the functions of activity setup, membership managing, forum managing, as well as online survey and diary, which are each time defined based on the needs of the customer. In addition, the summary and report of the activity are also needed for either to be delivered to customers or further learning and research purposes.

Consistent with the requirements of living lab process, Web 2.0 has its characteristics of user participation, added value, content control and social communication [14]. In the past years, with the fast development and improvement of the open source software, Wordpress has transformed itself from a blogging tool to a powerful content management system (CMS) with numbers of themes and plugins supporting all kinds of web-based functions [28]. Some of the most popular plugins include 1) Buddypress with package of features supporting the social network site development, 2) WooCommerce for building an online commercial site, and 3) WPML to setup a multiple languages web site. From technology point of view, the online user community system for supporting living lab process is established upon the webbased platform along with the requirements of the system roles and actions. Online user community system has its similarities with social media, but it also has its own needs in order to better support the user participation process and living lab services. All of these should also be considered when choosing the platform for the development of such online system, so that to have the feasibility and flexibility of customized functionality implementation. In general, PATIO system is aimed to connect the citizens as test users with the developers and researchers in terms of the user-centered innovation based on the real-life context.

\section{B. System Architecture}

Based on client/server architecture of the web applications [7], the system architecture of the PATIO is represented in the Figure 2. With the benefits of cost efficiency and flexibility, open source technologies are used in PATIO system integration, including MySQL for the database management, Apache as the Web server for accessing via Internet, and PHP as the middleware for the application development. Test users and system administrator access the PATIO via web browsers with digital devices, such as mobile

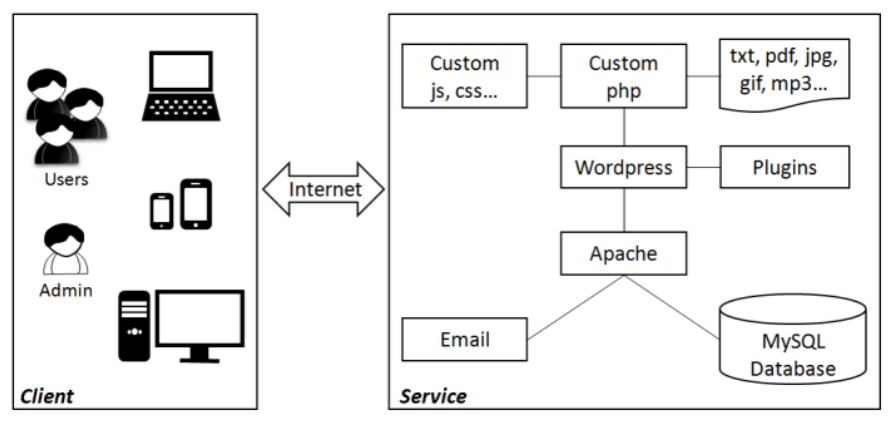

Fig. 2. The system architecture of the PATIO user community and user involvement tool

phone, tablet, laptop and PC. PHP as the middleware is used for the development of web-based applications.

As the CMS based on MySQL and PHP, Wordpress is a well-known open source platform with the primary function of blogging, and the powerful plugins to build up the social media kind of online user community. [23] This is also one of the main reasons why Wordpress was chosen as the framework of PATIO service. Based on the standard Wordpress package, plugins are either directly adopted or modified, with the customized theme and extra own developed functionalities, in order to match best with the requirements of the living lab system. The Wordpress contents and configurations are stored in MySQL database. In addition, the email server is established for the communication between the system and users.

\section{USER EXPERIENCE STUDY}

User experience (UX) is a significant factor for the product's success [19][30]. UX is defined as "person's perceptions and responses that results from the use and/or anticipated use of a product, system or service" [12], which means that it is beneficial to investigate users' experiences before, during and after the use [36].

We conducted a user experience study (survey and interview) to find out citizens' motivations to participate in PATIO online user community and its testing activities, and to compare the differences with motivations to participate in social network sites. PATIO enables combining the citizen forum and living lab activities together and it provides opportunities for user involvement in the design of the products and services in different development phases. The most important features of it are user recruitment, and a set of data collection tools such as online discussion forum (public/private), user diaries and surveys. The aim of the tool is to enable companies, research groups, and public organizations to easily reach suitable test users for different development activities.

\section{A. Survey and Respondents}

To find out the features which encourage user participation in online user community, user motivation survey was conducted via PATIO. The questionnaire consisted of 26 questions in total. It was designed with close-ended (21) and open-ended questions (5) in both English and Finnish. Six of 


\section{Age distribution}

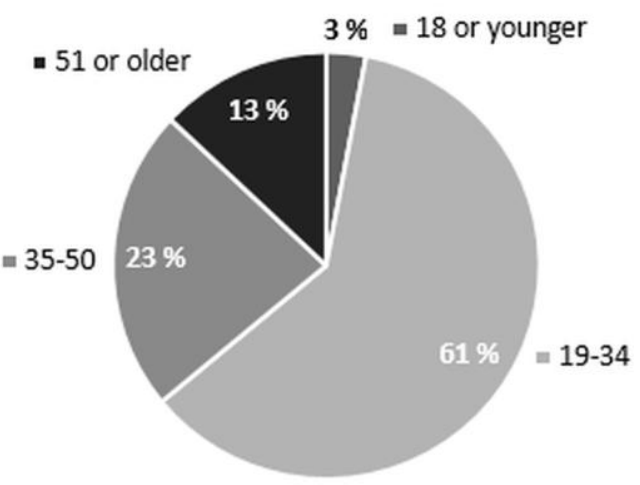

Education

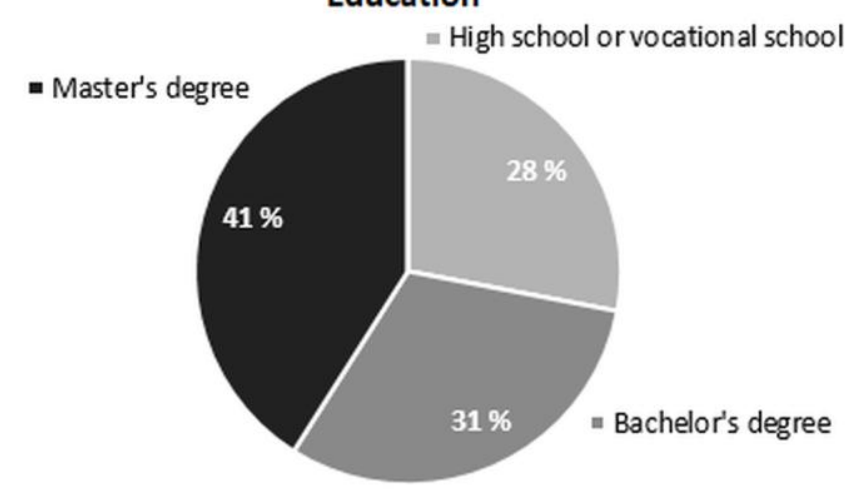

Employment status

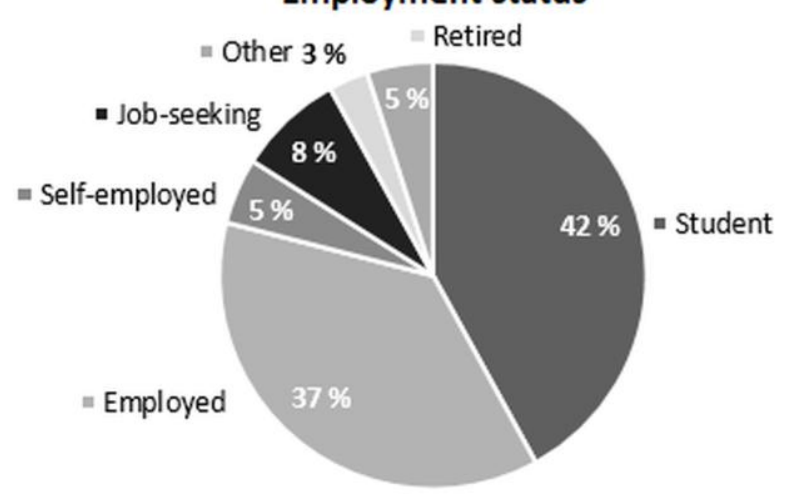

Fig. 3. Users' age distribution, education and the status of employment

the questions were focusing on background information. The following 20 questions were related to user participation habits and motivations. The questions charted, for instance, following aspects: rewards, recommendations, user interface design, feedback of participation, motivations, sharing, visiting activity, among others. In the close-ended questions, the opinion was scaled with 5-point Likert-scale, where 5 was strongly agree and 1 was strongly disagree.

The survey was launched in PATIO webpage and an invitation to participate was sent to all community members in total of 535 (the situation during the study). 53 PATIO members enrolled in the project and 39 valid responses were received, of which seven were in English and 34 in Finnish (native language of online users). Majority of respondents were male (59\%). Most of the respondents belonged in age group from 19 to 34 (62\%). Second highest amount of

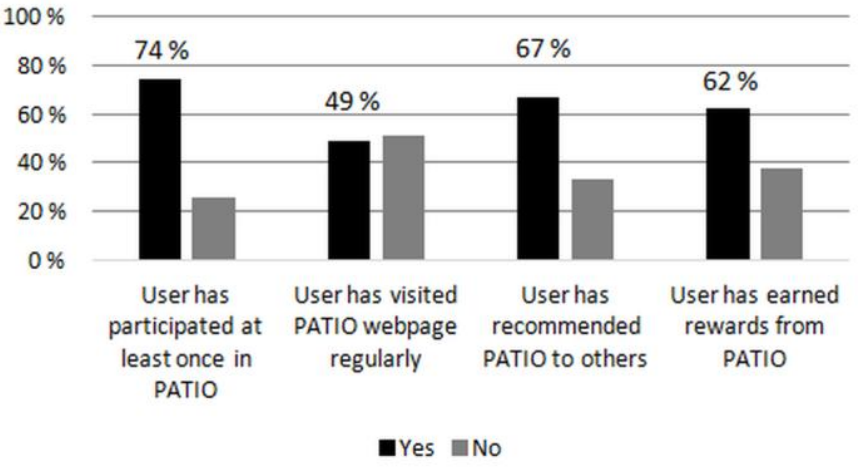

Fig. 4. Users' background relating to prior use of PATIO service

respondents belonged in age group from 35 to 50 years old (23\%) (Fig. 3). 74 percentage of the respondents (R) had participated at least in one test projects arranged via PATIO (Fig. 4.)

\section{B. Interview and Participants}

The semi-structured interview was conducted in order to investigate users' opinions and experiences of PATIO. In addition, the aim was to study attitudes and prior experiences with social media. Topics of interview related to the following issues: background information (age, occupation, use of ICT products), social media (e.g. "liking", sharing) and the use of PATIO (e.g. what makes activities interesting, motivation to attend on-site testing and perceptions on rewarding system).

The call for interviews was launched on PATIO webpage as a testing activity. Among all the applicants, 15 interviewees with different backgrounds were chosen in order to make sample more varied. Due to three cancellations, finally 12 participants (P) were interviewed. There were 50/50 ratio between native and non-native citizens. Interviewees' ages varied between 25 and 63 with the mean of 32. Eleven participants were male. The interviews were recorded and transcribed.

\section{Analysis of the Data}

The data analysis was initiated from survey data and numeric values for responses were count and graphs were drawn. After that, the transcribed data was read and similar themes were highlighted from the text to explain the survey findings in more detail. This type of analysis allows to get more holistic understanding of the study case.

\section{FINDINGS}

In this chapter we present the findings from both survey and interviews, because they both focused on the user's motivations to use the PATIO. Participants were asked to give a comment on what would motivate people to participate more in PATIO. Many participants commented that the community itself is not well known, which makes it difficult to become a member and start participating in its activities. Therefore, it was suggested to advertise it more, as one respondent stated: "Wider and better informing. At least every citizen of Oulu should know what PATIO is, which is not the (current) case at 
least among my own friends. It (advertisement) certainly would increase the amount of members" (R8). Most of the respondents had heard about the PATIO promotion event $(36 \%)$ or from their friends or colleagues $(23 \%)$. For promoting PATIO, just one channel was not perceived to be enough in order to motivate diverse people to join in it. Even promotion events have been done and most of the people has been recruited via them, events should be initiated in different places to be able to get different kinds of people from various age groups with more diverse backgrounds. As one interviewee stated: "I think you have to use the Facebook, but it is not enough, you have to also go to the place where the people are (e.g. elder people), in physical, to tell (them:) please come to test this" (P7).

\section{A. Motivations to Participate in Testing Activities}

The mean values for reasons for joining test activities are illustrated in Fig. 5. Personal interests (4.4) and involvement in development (4.2) were seen as the most important factors for motivating the participation. Followed by learning new technology (3.9), giving feedback (3.9), and earning rewards (3.9). Respondents were keen to find out how beneficial their feedback was for the development activities of products. For example, one respondent wrote: "It would be nice to get feedback on how product ideas have been developed after the (user) tests and whether the given feedback was useful for the companies who arranged the tests" (R19). Another respondent suggested: "To be able to see what was the benefit of the test for the development of the product there could be a summary of the test results" (R18). Participants also thought that criterion for their participating is depending on their own expertise area (3.7). The least favorite factors were meeting people with same interests (2.8) and participation of friends (2.0).

Another issue affecting motivations to participate was the actual testing activities and their quality and frequency. Participants wished that the PATIO could offer them more diverse activities within shorter period of time. For instance one responder commented: "More variability in projects" (R9) and another wrote: "Possibility took part in different kinds of projects more often than once within three months" (R 28).

In question asking why people give up participating in testing activity, all three answering options got almost as equal mean values. Thus, the reasons for quitting activity before it stops were: too long duration (2.6), requires too much effort from the participant (2.6), and no feedback is given on the participation (2.5).

Our findings also suggest that people do not visit actively PATIO webpage to see what is going on there, but they need to be prompted to do that. In the survey, 95 percent of the respondents agreed that they get information of the new test projects via email send by the moderator of PATIO. As one interviewee explained: "I only go there (webpage) when they (moderator/personnel) send me an (invitation) email...which has a very short text about the testing project and if the title is something that I am keen on or I would like to learn more of, I go to the web page to see what it is all about." (P3). It was

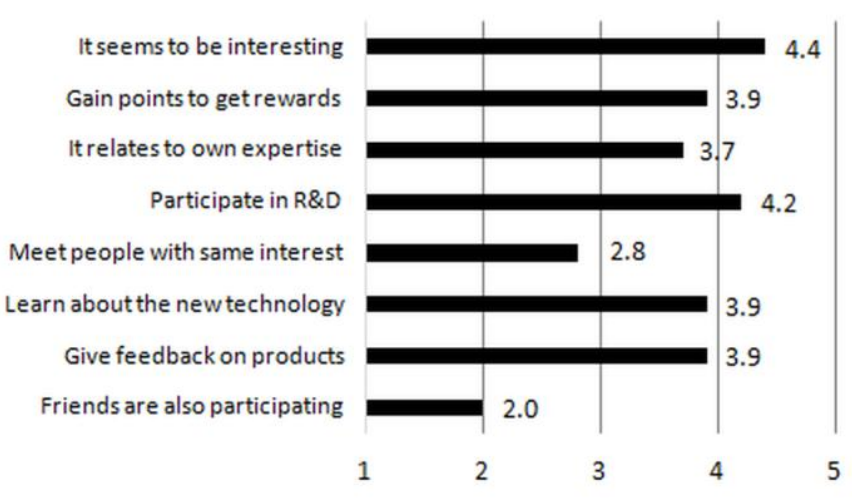

Fig. 5. Users' motivation to participate in living lab activities

interesting that for some the motivation to participate in testing activities was because of the moderator of the PATIO. One respondent commented: "Personal contact from organizers side is always motivating" (R15). Also people appreciated moderated activities, as one respondent stated: "I would like to have more supervised activities in projects, and the opportunity to ask questions and get answers from the project leader (moderator)" (R9).

\section{B. Motivation to Join On-site Evaluations}

Most of the interviewees claimed that instead of rewards the personal interests are more motivating factor to join test activities. As one stated: "I participate the testing project not for rewards but based on my interests." (P10). But for some rewards, such as cinema tickets (worth of $10 €$ ) are the main reason to take part in user studies, especially when they have to come to certain place in certain time to be able to participate. In on-site activities, the most important reasons for taking part were: willingness to see new design ideas, testing new technologies, and giving own opinions of the evaluated technology and design solutions. As one participant commented: "Test project group was full already, so I could not join, that was so sad... because I like to give my feedback when new things are developed. I think I have something to give." (P7).

For some participants, the face-to-face discussion was the motivating factor to take part on-site evaluations. For example, one participant explained: "I do not prefer those projects which are like forum based where there is some moderator there and asks questions, and you answer back. That's not for me, I want to do things" (P3).

One negative affect for on-site testing activity joining was the activity scheduling. As one of the interviewees had a problem with the testing time scheduling, a better activity calendar supporting tool was suggested as a solution.

\section{Motivation to Participate in Online Discussion Forum}

The mean values for factors which could encourage user to share ideas in the online discussion forum, Fig. 6 shows the results, where the involvement factor of could see my idea used in the new product or service gained the highest points (3.9) followed by the receive feedback during and after the 
5

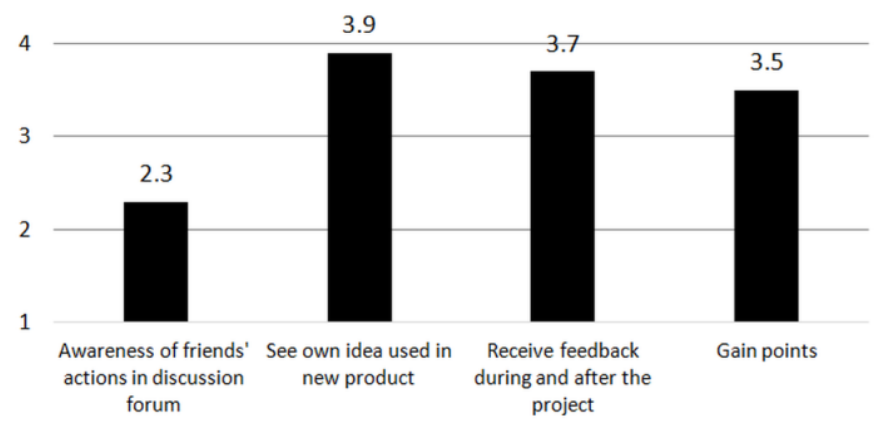

Fig. 6. Users' motivation to participate in discussion forum

project (3.7) and gain points (3.5). For over $25 \%$ of respondent's, rewards were not motivating factor for posting more ideas in the forum. The least favorite choice was awareness of friends' actions in discussion forum (2.3).

\section{Rewards}

In general, people were satisfied with the rewards that they will receive from on-site evaluations as well as being active member in PATIO. However, as the usual reward from on-site testing was cinema ticket (worth of approximately $10 €$ ), and it was also accessible with least points collected from being active member within user community, it might be a problem when participant is an active member, as s/he will get a lot of them. As one participant commented: "The rewards system is ok, but I have so many cinema tickets, it would be nice to have something else to choose from" (P6). Another respondent wrote: "I have so many cinema tickets already, and cause the movies are seldom interesting, I am afraid that tickets will not be used (as they are valid for certain period of time)" (R16).

With more points, active participants can get a gift card worth of $20 €$ to a certain shop. These gift cards were perceived to be good, but more variety of the gift card consumption places was suggested, for example to different clothing shops, grocery stores, online stores, and restaurants. Also gym-, bus-, and dining tickets were suggested as rewards especially for students who do not have a lot of money to be spend. Also concrete products were wished to be add as a choice for rewards or as a lottery gifts every now and then. Especially, testing activity related products were perceived to be interesting and as one respondent suggested, participants could get discount from them: "A significant discount for any product related to the project" (R14).

\section{E. Social Media Approach}

With the primary goal of collecting user opinions about the PATIO was perceived to have partly similar features as other social media sites. Those were, for example, the user profile, message and notification functions, activity following, as well as comment and reply functions in the forum. Also it was suggested that it could contain also more social media oriented tools, such as chat: "It would be nice to have some kind of online chat tool for project to connect more easily" (P12).
However only a few respondents wished to have more social media related features within PATIO. One respondent suggested: "Achievements" (R27) and another "The most active PATIO user of the month award" (R28). Some of the social media related features would be a good addition on PATIO. Over half of the interviewees were interested in idea sharing possibility in PATIO. However, awareness of friends was seen as unimportant factor of increasing user's willingness of idea sharing in the community.

Despite of similarities, for many interviewees PATIO is more professional site focusing more on testing of products and services than being a place for personal networking or networking between other users and companies testing their products. Participants indicated problems what bigger social networking sites can do for a smaller living lab user community which tries to integrate, for example, open forum where it would be chance to talk with test companies or other users. As one participant explained: "Well I am not that interested in talking in forum, and participating in free speech kind of sessions (in general)...(but) it might be interesting if the community is active enough. It's usually that FB and other kind of big social medias take people away from the forums that are more specific to some projects like PATIO" (P3). Another survey respondent wrote: "I do not have enough time and interest to participate in online and social media discussions" (R13). Also in the survey, choice options participation of friends (I join the activity because my other friends are also there) and meeting people with same interests were the least preferable choices to participate in test projects (see figure 5). Interviewees were not either interested in using their social media accounts for signing in for the PATIO even though most of them were using one or a few social media accounts actively for different purposes. When discussing about using social media accounts (e.g. Facebook, Google+) for other purpose, such as logging in games or some other online applications, participants' comments were divided. For some participants it meant convenient and easy login and sharing information with friends; while others did not like to do so due the concern of personal information loss and other security issues. As explained by one participant: "I tried sometimes (to use Facebook account to other purpose. e.g. games and applications) but I prefer to keep them separately" (P12).

\section{SYSTEM DESIGN AND IMPLEMENTATION}

This chapter present a new design of PATIO [27] with its functionalities based on system requirements and study findings. To meet the requirements mentioned earlier, key functional modules are designed and implemented for the PATIO system based on the architecture, with the aim of supporting the citizen participation process of living lab activities in terms of innovation creation. The key functions consist of 1) user profile template for user's personal information management; 2) activity and user management for supporting the living lab activity launching and user recruiting; 3) Template of forum, survey, and diary as the data collection method of the activity; 4) rewarding system in terms of user motivation. 


\section{A. User Profile}

User involvement is seen as one of the key elements of PATIO system. With the registration to the system, user profiles are stored in the database. Users are able to input and edit their personal information. The template includes both basic information (e.g. name, age, language, contact details, etc.) and the contents in related with the living lab activities, such as interests (new technology and product, public service, gaming industry, etc.), preferred testing method (online/onsite), personal digital devices and other settings. Summary of user reward points is also displayed in this view, while the actual functionality is carried out with the rewarding system, which is discussed later in this chapter.

\section{B. Enrollment Process and Activity \& User Management}

Besides the personal profile and settings, users are also able to access the activities what they are currently participating in or have been involved before. The "activity" here includes but is not limited to the user-involved testing of products and/or services in accordance with the customer's requirements. Participation of the activity is a mutual choice process, namely the needs of activity match with the interests of the users. The function flowchart is described in fig. 7 with two initial points to start the enrollment process. The activity invitation is displayed on user's profile page if he/she is chosen as the potential test user (more detail about user selection is described in the following section), and by accepting the invitation user is successfully enrolled in the activity. Otherwise, users can also search for the activities based on own interests, then send the request of the activity group membership to the system. If the activity is set as private group, once the membership request is approved, user is seen as enrolled. Whereas for the public activity which is open to all system users, membership approval is not needed. Users enroll into the public activity automatically once the request is sent to the system.

Wordpress plugins provide the features supporting group activity, where system users could apply the membership of certain group in order to enroll in the activity. With own customized functions, PATIO system is able to create group activity with project descriptions, testing instructions, and activity duration according to the requirements from customers. In addition, the PATIO system also enhances the functionality of searching/screening and inviting the target users from user database with certain pre-defined criteria, where the selection is based on the user profile information automatically. The invitation with short description of the activity is sent by system via email server to the matched users. Users who respond to the email invitation are either taken into group (mach the call) or excluded with the rejection (do not match the call) by the moderator (Fig. 7).

In the PATIO's user management module, all the enrolled and invited members of the activity are listed. Customized functions are designed to support the process of user invitation and recruitment. Likewise, the customized templates are implemented for the invitation, email and notification. Both activity management and user management are designed for the administrator and/or activity moderator to manage the basic information of the activities and participants, meanwhile

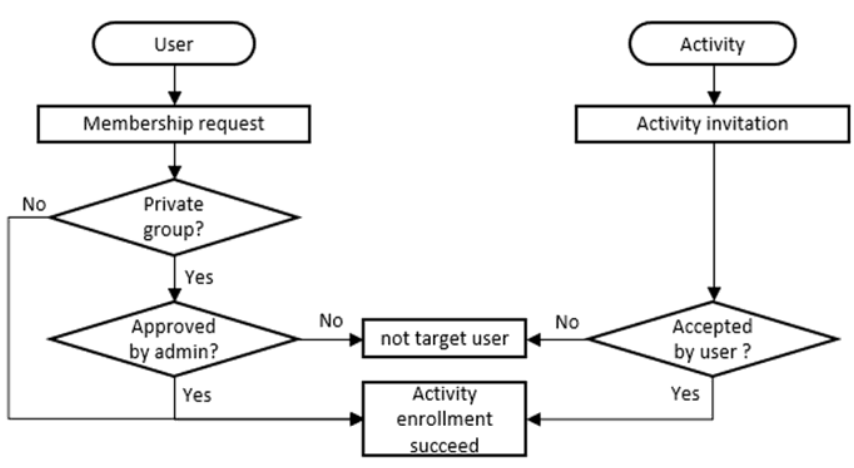

Fig. 7. Activity enrollment flowchart

user selecting and recruiting are seen as the starting phase of the citizen participation process.

\section{Forum, Survey \& Diary}

Besides the user recruiting function as mentioned earlier, the PATIO system also provides the possibility for the OULLabs to arrange not only the on-site testing event, but also the online studies (e.g. online forum discussion, survey, diary, etc.). PATIO users are able to participate and give their contribution to the activity by online. With the flexibility of open source software, self-developed functions and library functions are integrated into the PATIO system to support these OULLabs online activities, where the relevant data and information are collected. These functions are designed and applied in line with various research methods.

The social media kind of discussion forum is implemented for the focus group communication among the test users, developers, system administrator, and other related stakeholders. Differing from other social network sites like Facebook, the discussions in PATIO are often focused on certain topics, for instance, the ideas and comments of new service concept, the feedback and suggestions of new product, as well as other issues and concerns which are relevant to the activity. Therefore, in order to keep the activity theme under control, the discussion topic creation function is only open to the authorized roles, such as activity owner, project manager, and system administrator.

Survey and diary are typical data collection methods. To meet the basic functionality of data collection, integration of existing online applications is a feasible solution. Additionally, self-developed functions are also implemented to achieve the extra customized requirements of the system. However, with customized library functions, the time-cost and manpower to maintain and upgrade the system also need to be considered, especially in terms of the open source software development process.

PATIO service supports conducting online survey, group discussion and diary, which are accessible for only the activity group members. Users, who participate in PATIO activity, are able to answer the online survey and/or fill the online diary to give their valuable ideas, comments, and feedback to the tested products and services. The contents that users answer in the text box will be saved to the database. Moreover, only the diary owner and the activity administrator are able to view the diary contents, which is particularly suitable for the cases 
related to personal privacy. The diary template setup is done by the activity owner/creator with the activity management function. Data and information collected through survey and diary are presented as a part of the activity result report to the activity owner and system administrator.

\section{Rewarding System}

Since the goal of OULLabs is to support the innovation creation with citizen participation in real-life contexts, user motivation and engagement are seen as the key issues to be considered. Our UX study indicated that participants' intrinsic and extrinsic motivations, described by Füller [16], have influences on user involvement. In terms of OULLabs' activity, the intrinsic motivations include user interests and self-satisfaction, while extrinsic motivation refers to the rewarding system, in view of the fact that rewarding is seen as an effective way to encourage user participation in certain level.

The rewarding functionality in PATIO consists two primary components, which are the points earning and redeeming. Based on the general rewarding policy in OULLabs' PATIO, reward points are given to the users with certain criteria according to the goal and tasks of the activities, due to each activity may require different efforts and time spending of the participants.

From the system point of view, points are able to be hooked with the concrete actions of the activity, for example, user enrollment, user active level, amount of comments, task completion level (online and/or on-site tasks), and other contributions to the activity. This function supports both automatic points counting and manually adjusting from the system control panel. In the PATIO system, users can check the logs of the points earning, as well as redeem their points. PATIO system provides different choices for user to redeem points. Both customized functions and library components are applied to achieve the predefined functionality requirements.

\section{PATIO AS A PART OF OULLABS’ PROCESS}

One of the most crucial step in living lab process is the user recruitment, which is also seen as the starting point of the citizen participation. The PATIO is evaluated and developed in order to better support the citizen participation process of the innovation co-creation activities in OULLabs. The process includes five phases: negotiation, planning, testing, analysis and reporting (Fig. 1.). The contents of these phases are described in more detail in Figure 8. Moreover, the process supporting user involvement by the PATIO is presented in parallel with the phases of OULLabs (Fig. 8). The user involvement and engagement are highlighted (grey color), in terms of citizen participation in the innovation co-creation.

Once the project goals and needs are agreed between OULLabs and customer in the negotiation phase, the preparation of the activity will be initiated. According to the project plan, the activity is created in the PATIO system with the activity introduction, methods, and schedule. Activity management module provides the functionality of activity setup with predefined time period, discussion forum, and other optional methods depending on the needs. The innovation creation activity can be on-site event (e.g. workshop, focus

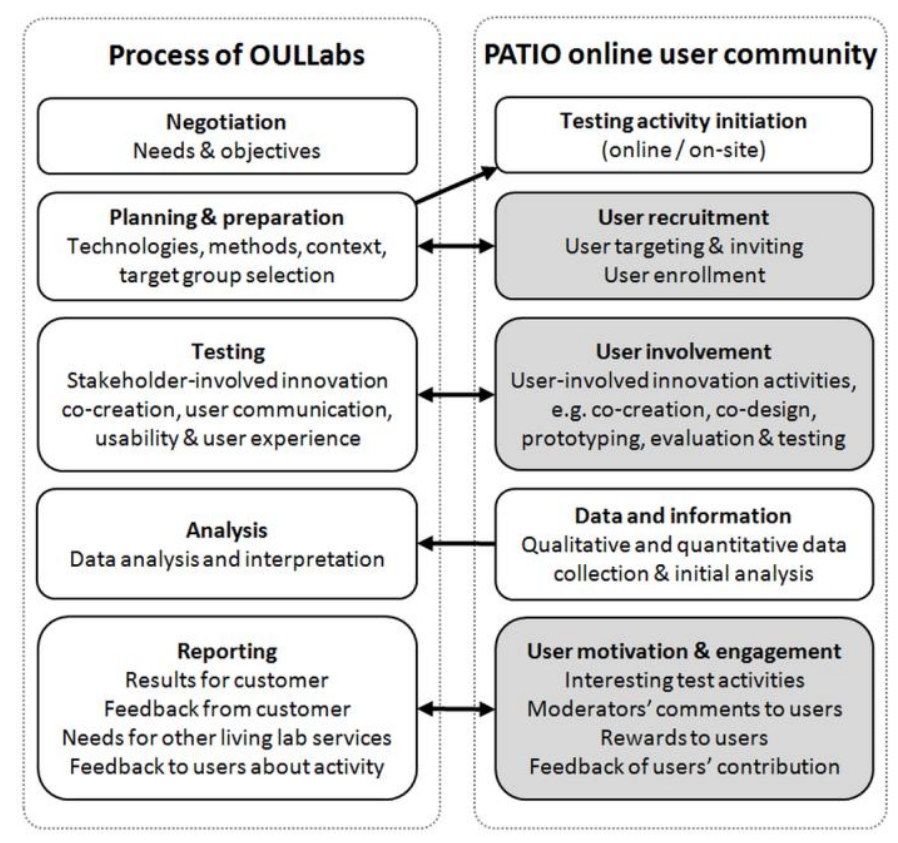

Fig.8. The process of OULLabs with user involvement supported (grey) by the PATIO online user community

group, interview, laboratory or field test), or online activity (e.g. survey, idea sharing, services evaluation), or as a combo of both on-site (field test) and online (diary or/and focus group discussion) studies. In any case, the activity initiation is done within the system, meanwhile the citizen participation process is started with the user recruitment.

Generally, in order to attract participants, the activities need to be promoted online and/or on-site depending on the circumstances. For example, the online activity of collecting citizens' opinions for one city's new service could be promoted through different channels of e.g. local newspapers, newsletters, social media, city library or related webpages and locations, and, in order to get more attention from the citizens who are the potential users of this new service. Since marketing is not the main focus of this paper, it is not discussed in detail. However, the citizens are able to register to the PATIO system anytime from different promoting channels through either OULLabs or its customers. Furthermore, once users register to the online system, their personal information will be stored in the user database, which means they will have opportunities to participate in other activities of OULLabs in the future. Meanwhile, the user database of PATIO is also continually increased with new registers of each new activity conducted.

In the planning phase, after the activity is created in the PATIO, user recruiting process starts with firstly targeting the users based on the activity requirements. As mentioned above, for some products/services testing activities, the target users need to be with certain conditions (e.g. residents live in certain region, senior citizens, or disabled people). In these cases, the PATIO can be used combining with other physical recruiting methods. Otherwise, in most cases, target users can be searched and selected through the PATIO system based on the predefined criteria. User management module is designed to support this phase, where invitation can be sent to all system users whose profile in the system match with the criteria. Once the invitation is accepted, the user is successfully enrolled into 
the activity group, and is ready to contribute to the innovation creation actions.

In the testing phase, the activity is conducted according to the plan. The methods and technologies are defined at the negotiation phase of the process, and prepared in the planning phase. Currently, the PATIO system mainly supports the activities with online focus group discussion, online survey and online diary. For the on-site innovation activities, such as workshop and field test, the online activity group provides a direct channel to keep close contact with the activity participants. The activity administrator can create topics in the group forum for the follow-up discussion with participants, as well as collecting suggestion and feedback from test users. Online survey is one frequently used method in OULLabs, where the survey can be conducted and controlled either by customer self or by the specialists of OULLabs. Online diary allows users to express their thoughts, feelings, emotions. Likewise they can give feedback about the PATIO system within certain time period. Online diary is often adopted for testing and evaluating products for a period of time, or other innovation activities which need a long-term data collection. In addition, differing from the group discussion which is public within activity members, the online diary is more private where the answers of users can be seen only by the activity administrator. It is important that along with the forum discussion, a researcher can also collect user experiences privately.

All the information and data collected from these different methods are stored in the PATIO system. In the analysis phase, the data is analysed by the specialists of OULLabs. Data collected from the activities and the analysis results will be presented and/or delivered to customers as part of the final reporting phase. Even though customers receive the final report only in the last phase of the innovation process, through the PATIO system, customers and other stakeholders (e.g. designer, developer, project manager, and researchers) are able to monitor all the contents produced in the activity group in real-time, and discuss with the activity participants whenever necessary. In the reporting phase, OULLabs and customer can discuss if there are needs for additional tests or other services of OULLabs.

Besides reporting the activity result to customers, another essential action in the last phase is the response to the activity participants, which includes both the rewards (e.g. rewarding points and/or prize) and feedback (e.g. activity result, followup information and action) for their contribution. These also match with the extrinsic and intrinsic motivations of user participation. According to the activity record from the PATIO system, once the activity is closed, all participants who have contributed to the activity will get their reward points in the system, which they can use to redeem for prizes through the PATIO system. Meanwhile after the activity has ended, customers are encouraged to share their follow up information, such as how the test results are used, what improvement comes out with the suggestions, to all the participants through the PATIO system. Correspondingly, users also can give own feedback regarding to the innovation activity they have been involved and/or the online system.

\section{DISCUSSION}

This paper introduced the process of OULLabs' and how the PATIO can support user involvement in each phase. We presented the UX study and its findings relating to citizens' motivations to participate in PATIO, and investigated how these motivations differ from motivations to participate in a social network sites. Our findings suggest that people do not see the PATIO system as the same as social media and their expectations of it are different. When building a successful online user community focusing on user involvement, our findings suggest that getting users to participate and become a member needs suitable kind of promotion, interesting and frequent test projects, and especially personal contact from user community.

\section{A. Motivation}

Our sample of results supports prior findings that to motivate users to participate in test projects, the projects should be interesting and stimulate curiosity and let people to learn new [21][22] [33]. The key intrinsic motivations for user participation willingness in PATIO were the personal interest, product development involvement, learning new ideas, and giving feedback. Rewards, however, were not that important motivating factor for the majority of the participants of our studies. In general, users were satisfied with the current rewarding system of PATIO, however, the improvement suggestions were also given, such as more options for gift cards and different kinds of vouchers for activities, transportation, and dining.

In case of smaller user communities, the testing activities might not be continuous, thus people might stop being active within the user community. It is suggested that intrinsic motivations are important also when establishing long-term engagement in living lab [33]. Our findings suggest that for keeping participants committed in PATIO, the frequency of the activities should be less than three months. This is an important issue and should be considered when trying to prevent people to get less active or even leave the user community. Should the online user community itself arrange some activities for keeping people committed? Also variety of activities is important for the members. Online forum discussion was perceived to be less attractive than on-site testing, as people valued more face-to-face feedback giving. To motivate people to participate needs actions also from companies who use online user community for getting access to suitable people to recruit them to their testing activities. Our findings suggested that people are interested in finding out how their feedback was utilized in the design of the product. Consequently, a long-term feedback system is required as the accelerator of user engagement.

Our findings suggested that the personal contact from moderator was valued even it was in form of email. The role of moderator is important in form of communicator between companies and test participants. Based on our findings, test activity would not be noticed at all without moderator. The members of PATIO even wished more moderated activities e.g. it was important that they can ask questions from moderator during the activities. Thus we argue that an online 
user community cannot be just a user database containing emails of the members, it needs to be an active forum guided by a professional moderator to allow a sense of belonging in the community.

\section{B. Social Media}

Our findings do not support prior findings suggesting that a sense of community is one of the most important factors affecting users' participation willingness in an online innovation community [3]. Our findings show that willingness of end-users to use PATIO as a communicating tool with other users in terms of relationship building is not prioritized. Instead, the feedback giving and follow up information from activity side are more relevant for users. In addition, the online living lab community tends to be more citizen based, where users are represented with real identity, especially in real-life testing activities. This has the significant difference when compared to social media, as in social media people may or may not represent themselves with the real identity. In fact, people saw PATIO as more professional service than social networking sites, which are focused on personal communication. However, PATIO could be connected with social networks to encourage users to recommend and share its information with others easily, and possibly to gain rewards by doing so.

Despite of having shared characteristics with social networks, online living lab community is not the same as social media, and cannot be replaced by social media. Comparing with the unstructured contents created by the users, the contents of online living lab community are often tightly related to the testing activities with structured process and schedule, as well as predefined goal and expected results, which are required and provided by customers and researchers.

When compared to social networks, the goal of PATIO is in relation based on individual interest of particular topics in certain level, with intrinsic and extrinsic motivations. PATIO differs from social networks by the duration of activities and scheduling of the activities. Trust, responsibility, and technological skills are key factors in both PATIO and social networks. Within these, sharing and evaluation, feedback and contribution, as well as involvement are highlighted in PATIO, especially in activity participation in the real-life contexts.

Online living lab community has similarities with social media, however, it has its own special characteristics and specific needs, which makes it different from social media. According to Dube [8], the characteristics of social media is that it is user-based. This matches also with the concept of online living lab community, concerning of the motivation and activeness of user participation for giving own opinions and suggestions. Similarly, as social media, the online living lab community is also based on trust and reputation [29] within an open and community-driven environment [35]. Common interest is the key factor of gathering users in the living lab community. Interest can be related to the technological, product, game, or public service development. The interaction with system is needed for user to contribute in the community [8]. Consequently, for building up the online living lab community, all the factors what have been discussed above should be concerned carefully.

\section{Evaluation of the new version of PATIO}

We briefly report preliminary results of the evaluation of the new version of PATIO. We conducted a testing activity for the "Electorate - The civic engagement application", which gives citizens a gamified and equal tool to express opinion and to follow decision making [9]. In this activity, we used PATIO forum for collecting participants' comments on the mobile application idea and image examples of it, as well as feedback of use of the PATIO. In this activity we had 27 PATIO members and three moderators (one customer moderator and two PATIO moderators).

We initiated the forum by adding six application related topics with a set of images and questions. In the fifth day of the testing period we added one additional image example with questions. In addition, we had PATIO related question and a feedback channel. During the one week discussion period, we received 153 comments, from which 91 was from PATIO activity members, 44 from customer moderator and the rest from the PATIO moderators. 33 percentage of members were very active in the forum discussion as each of them commented from six to 13 times. 19 percentage of members contributed by giving two to three comments and "liking" others' comments. 48 percentage of member did not commented at all, instead they just followed the discussion and "liked" others comments. Those members who commented only one or two times or not at all, said that they followed the discussion, and when they noticed that their thoughts are already mentioned, they did not wanted to repeat the same thing.

Feedback from activity members and the customer moderator of this Electorate activity [27] support the findings reported in this paper in terms of motivations to use and a role of moderators in motivations. For instance, participants' main reasons to join to the test activity were: a topic was regarded as interesting; own interest to give feedback on R\&D and participation to the activity was perceived to be easy. Participants were very pleased that customer and PATIO moderators answered actively to their comments and asked additional questions. This interaction was perceived as useful also from a customer point of view, because the customer moderator was able to ask more detailed questions in realtime. This enabled the customer to utilize feedback immediately in the development and also notice how interested citizens are in their application.

This preliminary evaluation of the new version of PATIO supports our earlier findings. However, in order to provide more universal results or guidelines, we need to conduct more diverse test activities and collect more feedback of PATIO.

\section{Limitations and Future Research}

We acknowledge that our sample of UX study was small compared to larger living labs, and that our findings are related to PATIO system and we have utilized them in our system development. However, we wanted to share these findings in order to provide insights how to develop and improve online 
user community in order to motivate participants to stay and be active in community. In future, it would be important to conduct more experiments with an improved version of PATIO with the current amount of community members $(1000+)$.

In future studies, the role of the moderator as a motivating factor in user participation should be investigated in more detail, for instance, to be able to create guidelines for successful and active participation enabling online user communities. Also the more rigorous comparison with social networking sites and online user communities should be done to understand their differences in more detail.

Moreover, in the further research, it is important to investigate different methods that can be applied in PATIO for collecting user experiences in different study contexts, for instance, in virtual or augmented reality studies. Likewise, it would be very beneficial to investigate PATIO activities in international test settings, for instance, between Finland and Russia, for example, involving citizens from both countries who are interested in learning of Karelian language and culture.

\section{CONCLUSION}

In this paper, we introduce a process of Oulu Urban Living Lab and how the PATIO online user community can be utilized in user involvement in different phases of innovation co-creation process. Also, the system requirements and architecture, as well as the design and implementation of the new version of PATIO are presented. Also, we share the findings of users' motivations to participate in an online user community, and discuss of similarities and differences between social networking sites and online user community. Findings show that to be able to create active participation enabling online user community the role of the moderator should not be neglected. In addition, our findings suggest that an online living lab community has similar characteristics as social media, but it requires more specific functions to fulfill the needs of all the stakeholders in the living lab environment. The differences between online living lab and social network community are related with user motivations, and the needs of the customers and researchers for living lab activities. Even though our sample of participants was relative small, we want to share these insights for the research and development audience.

\section{ACKNOWLEDGMENT}

We would like to thank our funder The Six City Strategy Open Innovation Platforms project and all the participants of our studies for providing valuable feedback for us of our living lab development process. We warmly thank the Electorate pilot project for a possibility to evaluate the new version of PATIO during the testing activity of their civic engagement application.

\section{REFERENCES}

[1] Alcotra innovation. 2013. Living Labs. Retrieved June 2016 from: http://www.alcotra-innovation.eu/livingLabs.shtml.
[2] Almirall, E., Lee, M., and Wareham, J. 2012. Mapping Living Labs in the landscape of innovation methodologies. Technology Innovation Management Review, 2.9 (Sep 2012), 12-18.

[3] Antikainen, M. 2011. Facilitating customer involvement in collaborative online innovation communities. Doctoral Thesis, No 760, VTT Publications.

[4] Ballon, P., Pierson, J., and Delaere, S. 2005. Open innovation platforms for broadband innovation: Examining European practice. In Proc. of 16th European Regional Conf. by the International Telecommunications Society (Porto, Portugal, September 04-06, 2005). (ITS'05).

[5] Ballon, P. and Schuurman, D. (2015). Living Labs: concepts, tools and cases. Info 17, 4, editorial. DOI= http://dx.doi.org/10.1108/info-04-2015-0024.

[6] Bergvall-Kåreborn, B., Eriksson, C. I., Ståhlbröst, A., and Svensson, J. 2009. A Milieu for Open Innovation-Defining Living Lab. In Proc. of the 2nd ISPIM Innovation Symposium, (New York, USA, December 06-09, 2009.) ISPIM'09. 6-9.

[7] Bulger, B., Greenspan, J. and Wall, D. 2003. MySQL / PHP Database Applications, 2nd Edition.

[8] Dube, R. 2016. Characteristics of Social Networks. Retrieved July 2016 from: http://socialnetworking.lovetoknow.com/Characteristics_of_Social Networks.

[9] Electorate - The civic engagement application. Retrieved March 2018 from: https://www.electorate.eu/?lang=en\#.

[10] European Network of Living Labs (ENoLL). 2013. About us. Retrieved July 2016 from: http://www.openlivinglabs.eu/aboutus.

[11] Eriksson, M., Niitamo, V.-P., and Kulkki, S. 2005. Living Labs. Retrieved July 2016 from: http://www.vinnova.se/sv/Arkiv/Genomforda-program/LivingLabs/.

[12] ISO DIS 9241-210:2010. Ergonomics of human system interaction - Part 210: Human-centered design for interactive systems. ISO, Switzerland.

[13] Følstad, A. 2008. Towards a Living Lab For Development of Online Community Services. The Electronic Journal for Virtual Organizations and Networks, Special Issue on Living Labs, Volume 10, (August. 2008), 47-58.

[14] Firpo, D., Kasemvilas, S., Ractham, P. and Zhang, X. 2009. Implementation of an online intellectual community in a graduate educational setting. In Proc. of the 2009 ACM SIGMIS CPR Conf. on Computer Personnel Research, 63-71. DOI= $10.1145 / 1542130.1542142$

[15] Fischer, E. and Reuber, A. R. 2011. Social interaction via new social media: (How) can interactions on Twitter affect effectual thinking and behavior? Journal of Business Venturing, 26, 1 (Jan. 2011), 1-18. DOI= http://dx.doi.org/10.1016/j.jbusvent.2010.09.002.

[16] Füller, J. 2006. Why Consumers Engage in Virtual New Product Developments Initiated by Producers. In NA - Advances in Consumer Research, 33, eds. C. Pechmann and L. Price. Association for Consumer Research, Duluth, MN, 639-646.

[17] Haukipuro, L., Shabalina, I.M., Ylianttila, M. Preventing social exclusion for persons with disabilities through ICT based services. In Proc. 6th International Conference on Information, Intelligence, Systems and Applications (IISA), Corfu, 2015, 1-7.

[18] Haukipuro, L., Väinämö, S., Arhippainen, L., 2014. Living Lab as One-Stop-Shop in the Development of Public Services. ISJ Interdisciplinary Studies Journal, A Special Issue on Smart Cities, vol. 3, no. 4 (ISSN 1799-2710).

[19] Jordan, P.W. Designing pleasurable products, An introduction to the new human factors. NY, Taylor \&Francis, 2000.

[20] Karaseva, V., Seffah, A., and Porras, J. 2015. A social-mediabased living lab: an incubator for human-centric software engineering and innovation. In Proc. of the 2015 International Conf. on Software and System Process (Tallinn, Estonia, August 24-26, 2015). ICSSP'15. ACM, New York, NY, 194-198. DOI=http://dx.doi.org/10.1145/2785592.2795367.

[21] Laizane, S. and Haukipuro, L. 2012. Preliminary experiences with the online forum PATIO in a multi-contextual Living Lab environment. In Proc. ISM2012 workshop Innovation through Social Media, December 1-2, 2012, Oslo, Norway.

[22] Lievens, B., Baccarne, B., Veeckman, C., Logghe, S., and Schuurman, D. 2014. Drivers for end-users' collaboration in 
participatory innovation development and living lab processes. In Proc. of the 17th ACM Conference on Computer Supported Cooperative Work, Workshop Designing with Users for Domestic Environments. (CSCW'14). 1-6. Retrieved July 2016 from: http://hdl.handle.net/1854/LU-4304649

[23] Michailidis N. P., Nathanailidis C., Papadopoulos I. and Tsiatsos T. 2013. Teachers' support using interaction analysis and visualization tools in educational group blogging. Global Engineering Education Conference (EDUCON), 2013 IEEE, 2 vol. p. 790-797. DOI= http://dx.doi.org/10.1109/EduCon.2013.6530197

[24] Näkki, P. And Koskela-Huotari, K. 2012. User participation in software design via social media: Experiences from a case study with consumers. Transactions on Human-Computer Interaction 4, $2,129-152$.

[25] Oinas-Kukkonen, H and Oinas-Kukkonen, H. 2013. Humanizing the Web: Change and Social Innovation. Palgrave Macmillan, New York, NY.

[26] Pallot, M., Trousse, B., Senach, B., and Scapin, D. 2010. Living lab research landscape: From user centred design and user experience towards user cocreation. In Proc. of the First European Summer School" Living Labs" (Paris, France, August 2010).

[27] PATIO. Retrieved March 2018 from PATIO: www.patiolla.fi.

[28] Patel, S.K., Rathod, V. R. and Parikh, S. 2011. Joomla, Drupal and WordPress - a statistical comparison of open source CMS, 3rd International Conference on Trendz in Information Sciences \& Computing (TISC2011), page 182 - 187 . DOI= http://dx.doi.org/10.1109/TISC.2011.6169111

[29] Pettenati, M. C. and Cigognini, M. E. 2007. Social networking theories and tools to support connectivist learning activities.
International Journal of Web-Based Learning and Teaching Technologies (IJWLTT) 2, 3, 42-60.

[30] Pine, B.J. and Gilmore, J.H. Welcome to experience economy, Harward Business Review. July-August 1998.

[31] Schuurman, D., Baccarne, B., Marez, L. and Mechant P. 2012 Smart Ideas for Smart Cities: Investigating Crowdsourcing for Generating and Selecting Ideas for ICT Innovation in a City Context, Journal of theoretical and applied electronic commerce $\begin{array}{llll}\text { research, } & \text { vol.7 no.3, 49-62. DOI= }\end{array}$ http://dx.doi.org/10.4067/S0718-18762012000300006.

[32] Schuurman, D. and De Marez, L. 2012. Structuring user involvement in panel-based Living Labs. Technology Innovation Management Review 2, 9, 31-39.

[33] Ståhlbröst, A. and Bergvall-Kåreborn, B. 2011. Exploring users motivation in innovation communities. International Journal of Entrepreneurship and Innovation Management 14, 4, 298-314. DOI= http://dx.doi.org/10.1504/IJEIM.2011.043051.

[34] Ståhlbröst, A. and Holst, M. 2012. The Living Lab Methodology Handbook. Published by the SmartIES project, a transnational Nordic Smart City Living Lab Pilot. Vinnova, Stockholm.

[35] Tesorero, A. 2013. The Characteristics of Social Media. Retrieved July 2016 from: http://homeofservice.com/blogs/21/thecharacteristics-of-social-media/\#.VwT1TeJ95D8.

[36] Vermeeren, A., Law., Roto, V., Obrist, M., Hoonhout, J. and Väänänen-Vainio-Mattila, K. User experience evaluation methods: current state and development needs. In Proc. of the NordiCHI 2010. ACM Press, 2010, 521-530. 